\title{
COMO A SELEÇÃO DE PROFESSOR DE LIBRAS PARA ALUNOS SURDOS TEM DIFICULTADO A FORMAÇÃO DA IDENTIDADE POLÍTICA DESSES ALUNOS
}

\author{
Kledson de Albuquerque Alves -SENAI ${ }^{1}$ \\ Maria Gorete de Medeiros - UFCG ${ }^{2}$
}

\begin{abstract}
RESUMO
Perlin (2002) diz que não há homogeneidade identitária no grupo dos Surdos, pois nele existem diferentes identidades Surdas que mudam conforme as ocasiões. Para a construção dessas identidades sempre prevalece a identidade cultural, significando que a identidade Surda é o ponto de partida para identificar as outras identidades Surdas, uma vez que se caracteriza como identidade política e está no centro das produções culturais. Além de se constituir pela experiência visual, a aquisição desta identidade requer a participação nos artefatos da cultura surda, intérpretes de Libras e convívio com pessoas de identidades iguais. Lunardi (1998, apud SILVEIRA, 2006) reconhece que no ensino da escola de surdos é indispensável a presença do professor Surdo, pois, mais do que representar modelo de linguagem e identidade, também é um articulador do senso de cidadania que se estabelece num processo de relação social. O Decreto $\mathrm{n}^{\circ}$ 5.626/2005 garante prioridade para o candidato Surdo na seleção de professor de Libras, desde que, além de usuário desta língua, este tenha pelo menos curso superior na área. Mediante sentido equivocado atribuído à recomendação de que todos os candidatos devem concorrer em iguais condições, além de regras que cerceiam aos Surdos a oportunidade de cumprir todas as etapas do processo seletivo, o cenário político de concurso para professor de Libras contraria o Decreto e vem favorecendo mais aos candidatos ouvintes e/ou surdos com identidades híbridas ou flutuantes. Partindo de uma experiência real, esta apresentação pretende mostrar como a aplicação de concursos para professores de Libras para alunos surdos têm contribuído para enfraquecer a identidade Surda nas escolas brasileiras, mediante dispositivos que dificultam a seleção para o docente politicamente Surdo. Também oferta aclaramentos pautados na Legislação para Surdos em Concurso Público (CONADE, 2010) sobre como resolver este problema.
\end{abstract}

Palavras Chave: Seleção Professor de Libras, Ensino, Identidade Surda.

\section{HOW THE POUNDS TEACHER RECRUITING FOR DEAF STUDENTS HAVE HAMPERED IDENTITY TRAINING POLICY OF THESE STUDENTS}

\begin{abstract}
Perlin (2002) says there is no homogeneity in the group identity of the Deaf because it Surdas there are different identities that change with the times. For the construction of these identities always prevails cultural identity, meaning that the Surda identity is the starting point to identify the other Deaf identities, once characterized as a political identity and is at the center of cultural productions. Besides being the visual experience, the acquisition of this identity requires participation in the artifacts of the deaf culture, Libras interpreters and socializing with people of the same identities. Lunardi (1998, cited in SILVEIRA, 2006) recognizes that the deaf school education is essential the presence of the Deaf teacher, because more than represent template
\end{abstract}

\footnotetext{
${ }^{1}$ SENAI de Campina Grande-PB

${ }^{2}$ Universidade Federal de Campina Grande
} 
language and identity, it is also an organizer of the sense of citizenship that is established in a process social relationship. Decree No. 5,626 / 2005 ensures priority for the Deaf candidate in the selection of teacher Pounds, since, in addition to user of this language, it has at least higher education in the area. By mistaken sense assigned to the recommendation that all candidates must compete on equal terms, and rules that curtail the deaf the opportunity to fulfill all stages of the selection process, the political landscape contest for teacher Pounds contradicts Decree and has favored more candidates listeners and / or deaf with hybrid or floating identities. Starting from a real experience, this presentation aims to show how the application of competitions for Pounds teachers for deaf students have contributed to weaken the Deaf identity in Brazilian schools by devices that hinder the selection for teaching politically Deaf. Also clarification on offer guided by the legislation for the Deaf in public tender (CONADE, 2010) on how to solve this problem.

Keywords: Selection Teacher pounds, Education, Deaf identity.

\section{INTRODUÇÃO}

A Lei $n^{\circ} 10.436 / 2002$, regulamentada pelo Decreto $n^{\circ} 5.626 / 2005$, legaliza a Língua Brasileira de Sinais (Libras) como meio comunicação e de expressão das pessoas Surdas. Na perspectiva da Educação Surda, ser professor de Libras para alunos Surdos não consiste somente em ensinar esta língua, mas, também ensiná-los o que é ser Surdo Lunardi, (1998, apud SILVEIRA, 2006).

Mesmo havendo multiplicidade de identidade Surda, é o tipo de identidade Surda-Surda que reflete o parâmetro identitário Surdo que deve se constituir no padrão para a construção da identidade do sujeito Surdo, uma vez que é ela que reflete as característica sociais, políticas e culturais que representam o que é ser Surdo. Por isto utilizamos a denominação "identidade Surda-Surda" para dar ênfase a este padrão, pois quando se refere a este tipo de identidade Perlin (2010) a denomina de identidade Surda. Esta é a identidade que serve como o ponto de partida para identificar as outras identidades Surdas, uma vez que se caracteriza como identidade política e está no centro das produções culturais. É por isto que o Surdo que alcança esta identidade Surda é tão diferente do sujeito ouvinte nos aspectos linguísticos, sociais, políticos e culturais, sendo essa diferença que marca fortemente a diferença entre Surdos e ouvintes

No Brasil os concursos para professor de Libras têm colocado em seus editais dispositivos que consistem em barreiras que bloqueiam o sucesso do candidato SurdoSurdo e favorece o sucesso de sujeitos ouvintes e/ou de Surdos com identidades que apresentam características parecidas com a identidade dos ouvintes. Possivelmente, os 
resultados dessas seleções têm colocado nas escolas maior quantidade de professores de Libras ouvintes ou professores Surdos cuja identidade é mesclada com a dos ouvintes.

No ano de 2016 o autor deste artigo vivenciou um processo seletivo que refletiu a realidade da maioria dos demais concursos de professores de Libras que têm atribuído sentido equivocado à recomendação do Decreto 5.626/2005, quando diz que "todos os candidatos devem concorrer em iguais condições". Também que, nos seus editais, têm estabelecido regras que diminuem a oportunidade do candidato Surdo realizar todas as etapas do processo seletivo.

Esta situação seletiva de candidatos Surdos vem acontecendo mesmo numa realidade em que desde 2010 o país já conta com a regulamentação da Legislação para Surdos em Concurso Público (CONADE, 2010) que estabelece "a aplicação do princípio da acessibilidade à pessoa surda ou com deficiência auditiva em concursos públicos, em igualdade de condições com os demais candidatos” (Id, CONADE, 2010, p. 02). Daqui para frente este documento será referido como LSCP.

\section{Sobre as diferentes identidades Surdas}

Perlin (2002), explica que o processo de construção da identidade Surda é muito complexo numa sociedade em que o modelo de identidade ouvinte é considerado superior. Ressalta as identidades Surdas são formadas em ocasiões do tipo: Surdos filhos de pais Surdos; Surdos sem contato com outro Surdo; Surdos que nasceram na cidade, ou que tiveram contato com a Libras desde a infância; Surdos que já foram ouvintes e ficaram surdos depois que já dominavam a língua portuguesa, e por aí vai.

Em termos de identidade Surda original, a que prevalece é a identidade cultural que se caracteriza, também, como identidade política. Esta é denominada por Perlin de identidade Surda (é a que reforçamos como Surda-Surda). Sob esclarecimentos ofertados pelo Estudo Surdo, bem como sob o respaldo dos aclaramentos contidos na LSCP, a referência de Surdo que precisa ser priorizada para o ensino da Libras aos alunos Surdos é aquele que possui a identidade Surda-Surda.

Os tipos de identidades Surdas relevadas por Perlin (Id.), são: Identidades Surdas; Identidades Surdas Híbridas; Identidades Surdas Flutuantes; Identidades Surdas Embaraçadas; Identidades Surdas de Diáspora; Identidades Intermediárias. Oferecemos 
as principais características apenas dos tipos dos Surdos candidatos a concurso para docência de Libras.

O tipo de identidade Surda-Surda é fortemente marcado pela política Surda e é mais presente em Surdos que pertencem à comunidade Surda. Apresentam características culturais como: têm experiência visual que estabelece seus comportamentos, cultura, língua, dentre outros; são usuários assíduos da Libras, como forma de expressão, e nunca utilizam o aparelho fonador. Aceitam-se como Surdos e se assumem como tal. Ressaltam suas diferenças assumindo suas necessidades em relação ao apoio de intérprete, de educação diferenciada, de Língua de Sinais; passam aos outros Surdos a sua Cultura e sua forma de ser diferente; tomam para si uma posição de resistência e assumem uma posição que avança em busca da demarcação da identidade cultural; pouco ou nada conseguem assimilar da ordem da língua falada e têm dificuldade de entendê-la; decodificam todas as mensagens recebidas em Língua de Sinais; sua escrita em português, como segunda língua, obedece à estrutura da Língua de Sinais, pode igualar-se à língua escrita, mas com reservas; têm suas comunidades, associações e/ou órgãos representativos e compartilham entre si suas dificuldades e desejos; usam tecnologia diferenciada como legenda e Sinais na TV, telefone especial, campainha luminosa; têm diferente forma de relacionar-se com pessoas e com animais. No caso da identidade Surda genealógica, os sujeitos trazem sinais vividos e provados durante gerações. Dentre estes estão os Surdos que nasceram de pais também Surdos; aqueles que nasceram Surdos e têm família ouvinte e entraram em contato com a comunidade Surda já em idade adulta.

Os Surdos de Identidades Surdas Híbridas, Flutuantes, Diáspora e Intermediárias apresentam algumas características diferentes daqueles que possuem Identidade SurdaSurda. Algumas dessas diferenças em muito comprometem a representação da identidade original do povo Surdo. Agrupando algumas dessas características podemos dizer que alguns nasceram ouvintes e depois ficaram Surdos por um motivo e, dependendo da idade em que adquiriram a surdez, conhecem a estrutura do português falado, decodifica mensagem em português e, vez ou outra, emitem ou captam mensagem na forma da língua oral; alguns assimilam mais a ordem da língua falada do que outros; a escrita do português pode igualar-se à língua escrita, mas com algumas reservas.

RPI Revista de Pesquisa Interdisciplinar, Cajazeiras, v. 1, Ed. Especial, 532 - 542, set/dez. de 2016. 
Alguns não têm contato com a comunidade Surda e é outra categoria de Surdos, dado ao fato de não contarem com os benefícios da cultura Surda. Seguem a representação da identidade ouvinte e colocam os princípios dos ouvintes acima da comunidade Surda e, às vezes, compete com os ouvintes, pois assim se consideram. São vítimas da ideologia oralista, da inclusão, da educação clínica, do preconceito e do preconceito da surdez. Alguns têm contato com a comunidade Surda, mas a rejeitam.

As identidades Surdas de Diáspora ocorrem nos Surdos que passam de um país e/ou de um Estado brasileiro para outro, ou mesmo de um grupo Surdo para outro. É uma identidade muito presente e distinta, podendo ser identificada como Surdo carioca, Surdo brasileiro, Surdo norte-americano.

Alguns Surdos têm uma característica que não lhes permite a identidade Surda, pois a sua captação de mensagens não é totalmente pela experiência visual. Esses Surdos apresentam alguma porcentagem de surdez, mas vivem como os ouvintes; utilizam aparelhos de audição e de aumento de som para aproveitar resíduo auditivo e valorizam o treinamento da oralização; consideram o Surdo como culturalmente menos dotados e não entendem a necessidade de Língua de Sinais nem de intérpretes; não vivem a cultura Surda nem a Língua de Sinais, sendo que alguns a adotam por simples hobby.

\section{Contribuições da Legislação para Surdos em Concurso Público- LSCP}

A presidente do Conselho Nacional dos Direitos da Pessoa com Deficiência (CONADE), Denise Granja, na 69ª Reunião Ordinária, realizada em Brasília nos dias 15 e 16/07/2010, assinou a LSCP, enquanto Recomendação No 001, de 15/07/2010. Neste documento, dentre os considerandos que estão relacionados aos direitos legais das pessoas com deficiência, também estão os que são relacionados às pessoas Surdas, inclusive com citação da Lei da Libras (Lei 10.436, de 24/04/2002) e do Decreto 5.626, de 22/12/2005). Encerrando seus argumentos com o ressalte de que

CONSIDERANDO que, nos concursos públicos, a fim de garantir a igualdade de oportunidade, a todos deve ser proporcionado o direito à

RPI Revista de Pesquisa Interdisciplinar, Cajazeiras, v. 1, Ed. Especial, 532 - 542, set/dez. de 2016. 
completa compreensão do conhecimento que se deseja testar; Recomendação para garantir a aplicação do princípio da acessibilidade à pessoa surda ou com deficiência auditiva em concursos públicos, em igualdade de condições com os demais candidatos.

RECOMENDA QUE OS EDITAIS DE CONCURSOS PÚBLICOS contemplem o princípio da acessibilidade para garantir a igualdade de condições à pessoa surda ou com deficiência auditiva, como os demais candidatos, determinando expressamente medidas indispensáveis para remoção de barreiras que impeçam a plena e livre concorrência, sem prejuízo de outras que porventura venham a ser adotadas, como as abaixo enumeradas:

\section{Quanto à Língua}

Nos editais de concursos públicos, deverá ser explicitamente reconhecida, nos termos da Lei $\mathrm{n}^{\circ} 10.436 / 02$, e do Decreto 5.626/05, a Língua Brasileira de Sinais - LIBRAS como meio legal de comunicação e expressão de natureza visual-motora, com estrutura gramatical própria, constituindo sistema linguístico de transmissão de ideias e fatos; (...)

3. Quanto à aplicação de provas objetivas, discursivas e/ou de redação.

3.1. As provas devem ser aplicadas em Língua Brasileira de Sinais LIBRAS, com recursos visuais, por meio de vídeo ou outra tecnologia análoga, conforme as normas técnicas em vigor, disponibilizando, inclusive, intérprete habilitado para permitir o acesso ao conteúdo das provas, sempre que solicitado pelo candidato surdo ou com deficiência auditiva. (...)

4. Quanto aos critérios de avaliação

4.1. O edital deverá explicitar os mecanismos e critérios de avaliação das provas discursivas e/ou de redação dos candidatos surdos ou com deficiência auditiva, valorizando o aspecto semântico e reconhecendo a singularidade linguística da LIBRAS.

4.2. Deve-se considerar que a pessoa surda educada na língua de sinais, necessariamente sofrerá influências desta na sua produção escrita, tornando necessário o estabelecimento de critérios diferenciados de correção de provas discursivas e de redações, a fim de proporcionar tratamento isonômico aos candidatos surdos. Nesse sentido, deverão ser instituídos critérios que valorizem o aspecto semântico (CONTEÚDO) e sintático em detrimento do aspecto estrutural (FORMA) da linguagem, fazendo-se a distinção entre "conhecimento" e "desempenho linguístico".

4.3. Deverão ser previstos, na aplicação de prova discursiva e/ou de redação, mecanismos que indiquem ser o candidato com deficiência auditiva, sem que seja ele identificado nominalmente.

4.4. As provas de redação e/ou discursivas, aplicadas a pessoas surdas ou com deficiência auditiva, deverão ser avaliadas somente por Professores de Língua Portuguesa para Surdos ou professores de Língua Portuguesa acompanhados de um intérprete de Libras.

\section{Como os Surdos de Identidade Surda cultural têm sido bloqueados nos concursos} de professor de Libras para alunos Surdos

RPI Revista de Pesquisa Interdisciplinar, Cajazeiras, v. 1, Ed. Especial, 532 - 542, set/dez. de 2016. 


\section{Das características do concurso para professor de Libras em 2016}

O autor deste artigo vivenciou um concurso para professor de Libras, para uma escola municipal bilíngue de alunos Surdos de todas as idades. O processo abrangeu três etapas: prova objetiva (uma de conhecimento de Língua Portuguesa, outra de conhecimentos específicos à Libras e outra de raciocínio lógico); prova de títulos; prova prática de Libras.

O edital citou o Decreto $n^{\circ} 5.626$ de 22/12/2005, ressaltou a prioridade atribuída ao candidato Surdo. Porém, contrariou esse princípio quando fixou uma margem de somente três candidatos classificados na prova objetiva para fazerem as provas de título e a de prática de Libras, mas sem estabelecer uma margem para a participação dos candidatos Surdos.

Mesmo resguardando as condições previstas no art. 40 do Decreto ${ }^{\circ}$ 3.298/99, quanto à igualdade de condições de qualquer candidato deficiente com os demais candidatos "no que concerne ao conteúdo das provas, à avaliação e aos critérios de aprovação (...) e à nota mínima exigida para todos os demais candidatos”, o processo seletivo deixou à margem as características da realidade do candidato de identidade Surda-Surda.

Estabeleceu uma barreira linguística para o candidato Surdo quando aplicou em Língua Portuguesa escrita também as provas de conhecimentos específicos à Libras e a de raciocínio lógico. Mediante princípios estabelecido pela LSCP (CONADE, 2010), para garantir a igualdade de condições linguísticas com os demais candidatos, as provas de conhecimentos específicos à Libras e a de raciocínio lógico teriam que ser aplicadas em Libras. Assim, ouvintes fariam essas provas na sua língua materna e Surdos fariam na sua língua materna, que é a de Sinais.

Mesmo sob um discurso de defesa da igualdade de condições para sujeitos Surdos e ouvintes, a prática do concurso foi contraditória, pois ao candidato Surdo foi imposta condição de desigualdade de condições linguísticas com os demais candidatos ouvintes. Disto tudo, o curioso é que a seleção deveria mirar os candidatos que evidenciassem melhor proficiência em Libras. Quem é melhor do que um Surdo de identidade Surda-Surda para ter essa proficiência? Seria o sujeito que tem essa língua 
por natureza, mergulhado numa experiência visual prevalente; que depende de um meio gestual e visual para emitir e receber mensagens.

\section{Do resultado do concurso para professor de Libras}

Uma das questões da prova de conhecimentos específicos à Libras foi elaborada de modo que, em muito, dificultou ao Surdo interpretar o sentido que diferia dois itens consecutivos. Os textos inerentes a essas alternativas diferiam apenas na utilização do artigo definido "o" e pelo artigo indefinido "um".

- A fonologia das línguas de sinais é $\boldsymbol{o}$ ramo da linguística que objetiva identificar a estrutura e a organização dos constituintes fonológicos, propondo modelos descritivos e explanatórios.

- A fonologia das línguas de sinais é um ramo da linguística que objetiva identificar a estrutura e a organização dos constituintes fonológicos, propondo modelos descritivos e explanatórios.

De acordo com Brochado (2003, p. 309-310) o uso e o entendimento do sentido do artigo indefinido dificilmente são alcançados pelo Surdo. Para ele o entendimento da palavra "um" poderia ser atribuído à ideia de quantidade, pois o sentido indefinido é objeto estranho na Língua de Sinais (no caso Libras).

O processo que pretendeu oferecer iguais condições de avaliação para todos os candidatos, negou a acessibilidade ao candidato Surdo nas provas de conhecimentos específicos à Libras e na de raciocínio lógico, pois o que estava sendo avaliado era conhecimento específico, não conhecimento gramatical de português.

A regra de somente três primeiros candidatos classificados na prova objetiva prosseguirem nas duas etapas finais do concurso retirou o único candidato Surdo, classificado, do páreo. Mas, no final do processo, a terceira pessoa faltou à prova prática de Libras e a classificação do candidato Surdo ascendeu para o terceiro lugar (posição que lhe dá possibilidade de ser contratado na falta das duas pessoas que lhe antecedem). Contudo, a média final do Surdo foi calculada em condições de desigualdade em relação às outras duas pessoas. Isto porque o Surdo também não pôde ser avaliado pelos seus títulos acadêmicos nem pela prática (que naturalmente já tem) na Libras. 
Mediante o descrito nesta experiência, surgem duas questões: Qual teria sido mesmo a classificação do candidato Surdo, caso ele tivesse realizado as provas objetivas de conhecimentos específicos a Libras e a de raciocínio lógico em Libras? Qual teria sido mesmo sua ordem de classificação no resultado final se, também, tivesse sido pontuado pelos títulos contidos no seu Currículo Lattes e pelo desempenho que demostraria durante a prova prática de Libras?

\section{Conclusão}

O processo seletivo para professor de Libras que hora tem sido realizado no Brasil precisa adequar-se aos princípios propostos pela LSCP para também possibilitar a contratação de Surdos que sejam referência pura de identidade Surda. Isto porque, se o padrão de identidade Surda corresponde ao tipo de identidade que chamamos de SurdaSurda, ao ser submetido ao processo de ensino de Libras efetivado por pessoas ouvintes e/ou por Surdos, cuja identidade não se encontra completamente imersa na política e na cultura Surda, o aluno Surdo pode ser prejudicado na formação da sua identidade Surda porque para grande parte dos Surdos, e, principalmente, para os mais jovens procedentes de famílias ouvintes, é na escola que têm a oportunidade de conhecer o padrão que define o que é ser Surdo-Surdo como contribuição para a formação da sua identidade Surda.

Nessas circunstâncias, como, nas escolas, pode acontecer a identificação do aluno Surdo com a identidade Surda mais pura e completa se não encontra no professor da sua língua uma representação firme da identidade Surda-Surda?

\section{REFERÊNCIAS}

BROCHADO, S. M. D. A apropriação da escrita por crianças surdas usuárias da língua de sinais brasileira. Tese de Doutorado. Universidade Estadual Júlio de Mesquita Filho, UNESP, São Paulo, 2003. Disponível em

$<$ http://tede.biblioteca.ufpb.br/bitstream/tede/8481/2/arquivo\%20total.pdf > (Acesso realizado em 07/09/2016).

CONADE. Legislação para Surdos em Concurso Público. 69ª Reunião Ordinária, realizada em Brasília nos dias 15 e 16/07/2010. Disponível em <http://reouvir.org.br/wp- 
content/uploads/2015/02/legislacao-para-surdos-em-concurso-publico.pdf> (Acesso realizado em 07/09/2016).

PERLIN, G. Identidade surda e currículo. In: LACERDA, Cristina B.F. de; GÓES, Maria Cecília R. de (Orgs.) Surdez - processos educativos e subjetividade. São Paulo: Editora Lovise, 2000. Disponível em

<https://repositorio.ufsc.br/bitstream/handle/123456789/88699/236381.pdf?sequence=1 > (Acesso realizado em 07/09/2016).

SILVEIRA, Carolina Hessel. Representações de surdos/as em matérias de jornais e revistas brasileiras. Anais do 2o. SBECE - Seminário Brasileiro de Estudos Culturais em Educação. Canoas: Ulbra, 2006. Disponível em

$\langle$ https://repositorio.ufsc.br/bitstream/handle/123456789/88699/236381.pdf?sequence=1 > (Acesso realizado em 07/09/2016). 